\title{
Las crisis de la Unión Europea: ¿una aplicación de la Ley de Murphy?
}

\author{
Sebastien Adins Vanbiervliet*
}

\section{RESUMEN}

En el presente artículo se postula que las diversas crisis que han estado afectando a la Unión Europea desde 2008 tienen causas esencialmente estructurales. Dos de ellas constituyen el objeto de este análisis. Por un lado, el regionalismo europeo atraviesa por una crisis de legitimidad a raíz de su carácter tecnocrático, el predominio del paradigma neoliberal en sus políticas y la falta de una identidad propiamente europea entre la población. Por otro lado, la UE enfrenta una crisis de orden geopolítico que engloba tres principales dimensiones: la creciente vulnerabilidad hacia sus vecinos del MONA (Medio Oriente y Norte de África); la reaparición de una lógica propia de la Guerra Fría respecto a Moscú y, en general, las mismas características del actual orden internacional.

Palabras clave: Unión Europea, euroescepticismo, eurocrisis, gobernanza, Rusia, MONA.

\section{The Crisis of the European Union: An Application of Murphy's Law}

\section{Abstract}

The present article suggests that the various crises that have been affecting the European Union since 2008 have essentially structural causes. Two of them are the subject of this analysis. On the one hand, European regionalism is experiencing a crisis of legitimacy due to its technocratic character, the predominance of the neoliberal paradigm in its policies and the lack of a properly European identity among the population. On the other hand, the EU faces a crisis of a geopolitical kind that includes three main components: the growing vulnerability towards the MENA; the reappearance of a "Cold War logic» in its relations with Moscow and, in general, the same characteristics of the current international order.

Keywords: European Union, euro-scepticism, euro-crisis, governance, Russia, MENA.

\footnotetext{
* Doctor en Ciencia Política por la Pontificia Universidad Católica del Perú, magíster en Relaciones Internacionales por la Universidad de Gante (Bélgica). Docente e investigador de la Pontificia Universidad Católica del Perú. Correo electrónico: sadins@pucp.pe
} 
La Unión Europea (UE) está pasando por un mal momento. Luego de que, aparentemente, la crisis económica iniciada en 2008 había tocado fondo, el bloque tuvo que pasar por otras tres principales crisis: en 2014 la crisis ucraniana, que puso en jaque las relaciones entre Bruselas y Moscú; la crisis de los refugiados de 2015; y, un año después, la crisis que generó el Brexit ${ }^{1}$, acompañada por el creciente éxito del euroescepticismo a lo largo del Viejo Continente.

El conjunto de estos sucesos parecen una ilustración de lo postulado por la Ley de Murphy: «cuando algo puede ir mal, saldrá mal». Si hasta mediados de la década pasada, varios analistas aún proyectaron a la Unión Europea integrada como la nueva superpotencia del siglo $\mathrm{XXI}^{2}$, en la actualidad brilla por su ausencia en varios dossiers que determinan la agenda internacional actual. El presente artículo, analiza dos principales problemáticas que están hipotecando el futuro papel de la UE en el concierto internacional: por un lado, la crisis (interna) del modelo de integración que ha seguido Bruselas en las últimas décadas y, por el otro lado, la crisis geopolítica (o externa) que está atravesando la Unión.

\section{La crisis del modelo de integración europeo}

\subsection{Antecedentes de un modelo elitista}

Si las primeras propuestas sobre una unificación política del continente europeo se remontan al inicio del siglo XIX, fue el contexto post Segunda Guerra Mundial que le dio forma al regionalismo europeo actual. En estos años, se hizo muy popular la tesis sobre una crisis existencial del Estado-nación europeo, considerado como principal responsable de las sangrientas guerras que habían destruido al continente y, además, como incapaz de elevar los ingresos y la prosperidad de sus ciudadanos (Moreno, 2009, p. 565). Fue en este contexto que Winston Churchill, en un discurso de 1946 pronunciado en Zúrich, hizo un llamado a construir unos "Estados Unidos de Europa» —esto sí: de la Europa continental, es decir: sin la participación del Reino Unido-.

Con el objetivo en mente de un Viejo Continente más unido se desarrollaría un debate muy rico sobre la estrategia que tenían que seguir los Estados europeos para llegar a este fin. Por un lado, liderados por el italiano Altiero Spinelli³ ${ }^{3}$ los federalistas

\footnotetext{
1 Por cuestiones de espacio, el presente artículo solamente analizará las principales crisis que enfrenta actualmente la UE como bloque. Por lo tanto, no se describirán las causas más específicas de la salida del Reino Unido de la Unión Europea.

2 Así, por ejemplo, en el año 2005, T. R. Reid publicó el libro The United States of Europe. The New Superpower and the End of American Supremacy.

3 Altiero Spinelli fue un miembro del Partido Comunista Italiano y como preso político del régimen fascista fue deportado a la isla de Ventotene, desde donde escribió el «Manifiesto de Ventotene», un hito en el movimiento federalista europeo.
} 
propusieron una integración inmediata, basada en una Asamblea Constituyente directamente elegida por la población europea, a fin de eludir los gobiernos nacionales, tomando como ejemplo a la Convención de Filadelfia de 1787. Mientras tanto, los llamados «intergubernamentalistas» pensaron en una cooperación profunda entre gobiernos, pero sin la cesión de soberanía. Durante el Congreso Europeo de La Haya, una iniciativa privada organizada en 1948 para reunir a políticos, empresarios y representantes de la sociedad civil se notó una clara preferencia por el pragmatismo intergubernamental, lo que resultó en la creación, meses después, del Consejo de Europa, cuya principal instancia sigue siendo el Consejo de Ministros.

Recién en mayo del año 1950 se empezó a materializar una alternativa frente a los dos enfoques, comúnmente conocida como el "Método Monnet», al ser Jean Monnet, un hombre de negocios y cabildero de la industria francesa, el principal promotor de esta estrategia. Según Monnet, inspirado por la teoría funcionalista de David Mitrany, Europa solo podía unirse de modo gradual, mediante uniones parciales ("pooling») en sectores económicos estratégicos tales como la industria pesada o la agricultura, administrados por tecnócratas dotados de poderes supranacionales. El resultado, una nueva autoridad equipada con el conocimiento científico y capaz de satisfacer las necesidades de la población — contrariamente a los Estados con su lógica territorial—, no solamente aumentaría el sentido de solidaridad entre los pueblos europeos, sino que también constituiría la base requerida para conformar una unión política. Esta visión constituyó la filosofía atrás del «Plan Schuman», dado a conocer por el entonces ministro francés de Relaciones Exteriores, y considerado como el fundamento de la Comunidad Europea del Carbón y el Acero (o CECA), creada oficialmente con el Tratado de París en 1951.

Como es sabido, la CECA no solo selló el fin de la lógica «suma-cero» que había predominado en la relación entre Berlín y París desde la unificación alemana, sino que también implicó la primera transferencia de la administración de un sector económico, indispensable para el desarrollo de los seis países miembros, a una agencia supranacional, la denominada «Alta Autoridad». Considerada como el principal organismo de la CECA y el precursor de la actual Comisión Europea, dicha autoridad originalmente estuvo conformada por nueve miembros, independientes de sus respectivos gobiernos nacionales, y tuvo como principal misión supervisar la ejecución del Tratado, es decir, la liberalización del mercado del carbón y el acero. Solamente recibió cierto contrapeso (intergubernamental) ante la toma de decisiones importantes por el Consejo de Ministros y, en mucha menor medida, por la Asamblea Común (hoy Parlamento Europeo) (Van Meurs et al., 2013, p. 46). 
Claramente contagiado por el entusiasmo generado alrededor de la CECA y considerado como una alternativa frente a un rearme alemán capaz de contener la amenaza soviética, en el año 1951 se propuso la creación de un «ejército europeo» bajo la dirección de una Comunidad Europea de Defensa (CED), cuyo liderazgo político caería en manos de la Comunidad Política Europea, luego de la redacción de una Constitución Europea. No obstante, la oposición frente a dicha iniciativa, muy ambiciosa para su época, tanto en la opinión pública, en Washington, como en algunas capitales de países miembros de la CECA, hicieron que no prosperara. Precisamente el fracaso de la propuesta de la CED tuvo una gran consecuencia para el regionalismo europeo: durante más de cuatro décadas estarían ausentes de la agenda europeísta los temas de defensa y seguridad (con la función de la OTAN como «paraguas de seguridad» estadounidense en Europa Occidental, el tema tampoco era demasiado urgente). Es así como, a mediados de la década de 1950 se vio un claro regreso del debate sobre asuntos económicos, aparentemente menos sensibles que los políticos y militares. Los Tratados de Roma de 1957 que dieron origen a la Comunidad Económica Europea (CEE), la Euratom, más la puesta en marcha de la Política Agraria Común cinco años más tarde fueron reflejo de esta tendencia.

Si las décadas de 1960 y 1970 se caracterizaron básicamente por la implementación de la Unión Aduanera, prevista en el Tratado CEE, y una primera ampliación del bloque (a la CE-9 en 1973), apenas hubo una profundización del proyecto integrador. Ello, más el inicio de la primera gran crisis económica en el Viejo Continente desde la Segunda Guerra Mundial, hizo este período fuese conocido por el estancamiento y profundo cuestionamiento del regionalismo europeo, como la etapa de «la euroesclerosis». Recién a partir del año 1984, con Mitterrand y Kohl instalados como nuevos ocupantes del «tándem» europeo y la llegada de Jacques Delors a la Presidencia de la Comisión Europea, se llegó a observar una reanudación de la dinámica integradora europea. De manera concreta, Delors propuso tres nuevos macroobjetivos para relanzar la Comunidad Europea: la realización de un mercado común europeo, es decir, un espacio económico con plena movilidad de personas, bienes, servicios y capitales, preferiblemente con una moneda única; una política económica y social integral; y una política exterior y de seguridad común.

De estos tres, el socialdemócrata francés consideró como más urgente la conversión de la CE en un mercado común, en su momento además el tema menos sensible de los tres (Van Meurs et al., 2013, p. 156). En su tarea no solamente obtuvo el apoyo de los grandes conglomerados industriales europeos, banqueros y empresas multinacionales, que desde antes habían manifestado su entusiasmo a favor de un mercado europeo unido y la desregulación nacional de las economías europeas, sino también de Margaret Thatcher, la primera ministra del Reino Unido quien consideró las 
nuevas propuestas como coincidentes con el paradigma neoliberal, del cual fue una de las principales defensoras en el continente, desde su elección en 1979. Finalmente fue el Tratado de Maastricht (TUE) de 1992, el que consolidó la nueva «Unión Europa» como un mercado común, con ciudadanía europea, dos nuevas dimensiones de cooperación (el denominado «segundo pilar» de «Política Exterior y de Seguridad Común» o PESC y un tercer pilar de "Asuntos de Justicia e Interior»), y —muy importante- las denominadas «normas de convergencia» que regularían el ingreso de las economías de la UE a la nueva Unión Monetaria Europea.

De las múltiples propuestas que figuraban en el TUE, dos obtuvieron una gran prioridad. Por un lado, la implementación del Tratado de Schengen, lo que significó la desaparición de los controles aduaneros y migratorios en las fronteras internas de los Estados afiliados, realizada en 1995. Por otro lado, a pesar del gran escepticismo entre varios políticos y economistas, se presenció la creación de la unión monetaria europea, primero con la elección del nombre de la nueva moneda —euro- en 1995, luego con la fundación del Banco Central Europeo en 1998 y, finalmente, con la entrada en circulación del euro en 2002. No obstante, la rapidez mostrada en este último proceso respondió más a una lógica geopolítica, que una monetaria-económica: en su esencia, la introducción de la moneda única fue la concesión que le hizo Helmut Kohl a François Mitterrand en 1990 cuando el entonces presidente francés expresó sus reservas frente a la reunificación de las «dos Alemanias». Probablemente el que mejor expresó el temor compartido por varios jefes de Gobierno europeos en aquel momento fue el escritor francés François Mauriac con su exclamación: «j'aime tellement l'Allemagne que je préfere qu'il y en ait deux!».

Así, y sin considerar sus prerrequisitos económicos, Mitterrand recuperó la idea de una unión monetaria europea, ya presente en el Plan Werner de la entonces CE de 1970, al considerarla una palanca para garantizar la encapsulación alemana en la construcción europea y así evitar un regreso del viejo «dilema alemán». Algunos analistas de la época explicaron este histórico compromiso de la siguiente manera: «el conjunto de Alemania para Kohl, la mitad del marco alemán para Mitterrand» (Ash, 2012, p. 6). Sin embargo, bajo insistencia del canciller alemán, el nuevo Banco Central sería una copia del Bundesbank: un banco central exento de cualquier tipo de injerencia política y además orientado hacia un solo objetivo: la estabilidad de precios, un claro reflejo del "trauma» alemán con la hiperinflación de la década de 1920 y en detrimento de la preocupación por el desempleo — que acompaña las políticas de, por ejemplo, el Federal Reserve- Helmut Kohl además insistió en la necesidad de fundar, de modo paralelo, una unión fiscal y bancaria a fin de disciplinar a los gobiernos en el aspecto macroeconómico y de poder coordinar la política económica como un bloque. Sin embargo, tal como afirmó Timothy Ash: «[...] 
France was having none of that. The point was for it to gain some control over Germany's currency, not for Germany to gain control over France's budget» (Ash, 2012, p. 6). Recién con la crisis de la moneda única a partir de 2008 quedarían claras las consecuencias de estas decisiones nefastas. Primero, se demostraría que una unión monetaria sin una unión fiscal o un mínimo nivel de armonización de las políticas macroeconómicas, no es sostenible a mediano plazo. Segundo, se observaría las dramáticas consecuencias sociales, sobre todo en las economías "periféricas» de la eurozona, de una política monetaria ortodoxa, exclusivamente orientada a la estabilidad de precios en el «centro» de dicha unión, agrupado alrededor de Alemania.

Cabe mencionar que, más allá de la profundización del principal proyecto regionalista europeo, también se vio una ampliación del mismo a partir de la década de 1990, primero con la incorporación de economías altamente desarrolladas (con la UE-15 en 1995), seguida por el así llamado Big Bang a través del cual ingresaron diez nuevos países - con la excepción de Malta y Chipre- ubicados en Europa Central (UE-25 en 2004) y finalmente, en 2007 y 2013, tres naciones balcánicas. De este modo, hasta la implementación del Brexit, la Unión Europea se compone de veintiocho Estados miembros.

\subsection{Las razones del euroescepticismo... y el alter-europeísmo}

Siendo la Comunidad, hoy Unión Europea, un proyecto claramente elitista desde sus orígenes, durante al menos cuarenta años disfrutó de un apoyo pasivo entre la población: una mayoría de ella consideró al proceso de integración europeo como una evolución inevitable a fin de mantener la paz en el continente, contener la amenaza soviética y garantizar su bienestar socioeconómico. No obstante, dicho consenso empezó a ser cuestionado a partir de la década pasada, cuando en varios referendos sobre el futuro de la Unión ${ }^{4}$, el electorado manifestaría su descontento sobre el proyecto. De modo paralelo, se vio el creciente éxito electoral de agrupaciones, tanto de tendencia ultraderechista - históricamente enfocadas en el tema migratorio y la inseguridad ciudadana-, como de la izquierda con posturas cada vez más críticas hacia Bruselas. Por último, también las encuestas que miden el apoyo popular frente a la Unión Europea - tales como el EuroBarómetro-, trazarían claramente un aumento del denominado "euroescepticismo»".

\footnotetext{
4 En un referéndum de 1992, apenas un 51\% de franceses aprobó el TUE. Luego, en 2000 y 2003, una mayoría de daneses y suecos, respectivamente, votó en contra de la introducción del euro. En 2005, tanto en Francia (55\%) como Países Bajos (62\%) se votó en contra de la propuesta de una Constitución europea. Finalmente, en 2008, un $53 \%$ de los irlandeses se opuso al Tratado de Lisboa.

5 El apoyo a la UE entre la población europea llegó a su punto más bajo en mayo de 2011 , cuando apenas $47 \%$ de los entrevistados consideró como positiva la membresía de su país en el bloque. Sin embargo, siempre han existido grandes diferencias entre los países a nivel de percepción de la UE. Así, en un estudio especial del EuroBarómetro de
} 
Antes de analizar las causas de esta tendencia, caben dos comentarios. En primer lugar, no todos los que critican a la Unión Europea, necesariamente deben ser tildados como «euroescépticos» o "antieuropeístas». También existe un grupo creciente de europeístas que busca una reforma de las instituciones europeas a fin de superar su "déficit democrático» y/o un cambio de las ideas-fuerza del bloque, a favor de políticas más sociales, justas y ecológicamente sostenibles. Para describir a esta tendencia que busca no menos Europa, sino una mejor Europa, se prefiere el concepto de «alter-europeísta» —en la línea con el movimiento alter-globalista que empezó a perfilarse en la década de 1990- En segundo lugar, ha sido innegable el avance del euroescepticismo a lo largo de los veintiocho miembros de la Unión Europea en la última década. Sin embargo, y contrariamente a lo que afirman algunos medios de comunicación, sigue siendo una tendencia minoritaria en la mayoría de países miembros. Como se sabe, inclusive en la nación históricamente considerada como más escéptica hacia el supranacionalismo bruselense, el Brexit solo se impuso con algo más del tres por ciento. Así también en las elecciones organizadas en 2017 en dos otros países con una tradición euroescéptica, Países Bajos y Francia respectivamente, claramente ganaron agrupaciones proeuropeístas. Además, algo muy manifiesto también durante el Brexit, el grado de euroescepticismo principalmente es dependiente de la edad y el grupo social: en general, los jóvenes y los mejor educados tienden a ser más europeístas.

En el presente artículo, se consideran tres principales causas del creciente euroescepticismo, aunque altamente interrelacionadas entre sí: primero, el carácter tecnocrático de las instituciones europeas (descrito por varios autores y políticos europeos como el «déficit democrático» de la UE); segundo, el predominio de la lógica neoliberal de las mismas desde la década de 1980; y, tercero, la falta de una «identidad europea», acompañada por un regreso de las lógicas nacionalistas en algunos países miembros del bloque.

Tal como se mencionó líneas arriba, la principal novedad que contrajo la CECA en 1951 se refiere a la creación de un organismo supranacional de carácter técnico, es decir independiente de las respectivas coyunturas políticas nacionales: la Alta Autoridad, renombrada "Comisión Europea» a partir de 1958. Si bien la Comisión no constituye el único organismo del sistema europeo, sí es considerado como el principal por las tres funciones que cumple desde sus orígenes: proponer legislación, implementar las decisiones — como un poder ejecutivo_ y defender los Tratados 
de la UE. En este sentido, la Comisión Europea ha sido un claro precursor de una dinámica, muy fortalecida durante las últimas dos décadas, que Luc Huyse ha descrito como «la emigración de la política». Según este politólogo belga, la toma de decisiones políticas le corresponde cada vez menos a las instituciones tradicionales, a saber: los parlamentos y los gobiernos nacionales. En su lugar ha aumentado el papel de los grandes consorcios empresariales multinacionales, de gobiernos subnacionales (mediante procesos de federalización o descentralización en varios estados del mundo), así como de una red de instituciones regionales y/o mundiales —entre otras, la Organización Mundial del Comercio, las instituciones Bretton Woods y la misma Unión Europea-. Estas últimas constituyen la base de una incipiente gobernanza transnacional, anónima y "despolitizada" por ser manejada principalmente por tecnócratas. Según el mismo autor, dicha transición de una lógica de gobiernos (governments) hacia una red de administraciones (governance) ha originado dos principales problemas, muy manifiestos actualmente en los países de la Unión Europea. Por un lado, se ha presenciado una gran fragmentación en el proceso de toma de decisiones políticas, debilitando así seriamente la capacidad del mismo Estado para enfrentar los problemas o desafíos, en aumento ante la volatilidad que caracteriza al actual orden internacional, que enfrenta la sociedad. Por otro lado, y aún más preocupante, mientras que las decisiones tomadas en el marco de esta gobernanza están generando un impacto inmediato sobre las vidas cotidianas de las poblaciones, apenas existe un control democrático sobre las mismas.

El poder legislativo de la Unión Europea está en manos del Consejo de Ministros (o Consilium) y el Parlamento Europeo, en sí difiere sustancialmente de un parlamento (nacional) tradicional, tal como afirma Stefan Rummens: «El Parlamento Europeo no solo difiere de otras cámaras legislativas de democracias parlamentarias porque carece de las potestades para establecer impuestos y dispensar dinero, para tomar iniciativas legislativas y para legitimar las acciones del gobierno, sino sobre todo por la ausencia de una dialéctica tradicional gobierno-oposición en la UE» (2016, p. 110, traducción propia). En consecuencia, al no tener un "gobierno» europeo o una verdadera oposición política en el seno de la UE, los mismos miembros del Parlamento Europeo, como únicos funcionarios de la UE directamente elegidos por la población, se presentan más como políticos «neutros», que guiados por algún pensamiento ideológico. O en palabras de Rummens: «El problema de la despolitización se resume muy bien con la boutade que governance en última instancia se reduce a una especie de government without opposition (2016, p. 115). Precisamente esta combinación de, por un lado, Estados y políticos nacionales privados de su histórico espacio de maniobra, y, por otro lado, una poderosa burocracia europea políticamente anónima y apenas responsable ante los ciudadanos, explica el creciente éxito 
electoral de candidatos populistas, nacionalistas y euroescépticos, no necesariamente acompañados por valores democráticos, pero sí más visibles e identificables por la población.

Mientras que la gobernanza transnacional descrita en los anteriores párrafos se autoproclama políticamente neutra y promotora de la eficacia y el buen manejo de la administración (good governance), en sí tiene un perfil marcadamente mercantilista y neoliberal. En el caso específico de la Unión Europea, fue con el Tratado de Maastricht de 1992 que el neoliberalismo se consolidó como principal paradigma en la formulación de las políticas comunitarias. Así, en nombre de la conformación de un mercado común europeo mundialmente competitivo, la UE, con la Comisión a la cabeza, empezó a actuar como el principal promotor de la privatización de un sinnúmero de empresas públicas — de sectores tan diversos como las telecomunicaciones, los correos, la energía, el transporte ferroviario, los puertos y las pensiones-, de la flexibilización del mercado laboral y la desregulación del sector financiero. Del mismo modo, con los denominados «criterios de convergencia» — mejor conocidos como «los normas de Maastricht»— que sirvieron como prerrequisitos mínimos para poder acceder como economía a la eurozona ${ }^{6}$, y la excesiva atención por la estabilidad de los precios del nuevo Banco Central Europeo, empezaron a predominar las «políticas de austeridad fiscal», vigentes hasta la actualidad, a pesar de haber mostrado sus efectos nefastos para las poblaciones más vulnerables durante la eurocrisis.

En vez de haber contribuido con una mayor convergencia entre las economías de la unión monetaria, en la práctica, la introducción del euro ha originado una creciente exacerbación de la brecha entre las economías del norte de Europa, lideradas por Alemania, y las de la periferia del bloque, señaladas de modo peyorativo como los «PIIGS» ${ }^{7}$. Al quedar excluida la posibilidad de una devaluación de la moneda, una reducción unilateral de los tipos de interés o de una política económica contracíclica, a los países en crisis solamente les queda disponible la devaluación interna, es decir, una política basada en los recortes salariales y la reducción del gasto público. El resultado: una recesión prolongada, un aumento de la deuda y, ante el cuestionamiento sobre la solvencia de dichas economías por los mercados financieros, mayores tasas de interés para pagar la misma deuda. En cambio, a pesar de que los electores del norte más rico de la eurozona pueden percibir lo contrario, las economías más desarrolladas de la Unión, en términos relativos, han ganado a partir de la crisis con un euro subvalorado, una tasa de interés baja y, sobre todo, un fortalecimiento de

\footnotetext{
6 Dichos criterios refieren a la tasa de inflación, el tipo de cambio, la deuda pública, el déficit presupuestario y el tipo de interés a largo plazo.

Durante la eurocrisis se usó el término en alusión a los cinco Estados más afectados por la crisis: Portugal, Italia, Irlanda, Grecia y España.
} 
su competitividad frente a los «socios» de la periferia. En este sentido, autores, como Hans Kundnani, (2015) afirman que ha vuelto el histórico «dilema alemán» con la aparición de Alemania como un nuevo «semihegemón geoeconómico» en el seno del regionalismo europeo.

Con la aprobación en 2012 del Pacto Fiscal Europeo, impulsado principalmente por la canciller alemana Angela Merkel y su ministro de Finanzas Wolfgang Schäuble, se llegó a institucionalizar aún más la supervisión sobre las políticas fiscales, presupuestarias y sociales de los países miembros por parte de las instituciones europeas. En la actualidad, los Estados miembros de la eurozona tienen la obligación de presentar, semestralmente, sus presupuestos a la Comisión Europea; de incorporar las políticas presupuestarias en su legislación nacional (con preferencia en sus constituciones); y pueden recibir, en caso de una violación de las normas, una multa de la Corte Europea de Justicia de hasta un 0,1\% del PBI (Rummens, 2016, p. 208). No obstante, una de las lecciones más amargas de la eurocrisis ha sido que Bruselas se mostrara dispuesto a sacrificar temporalmente la voluntad popular a favor de la estabilidad macroeconómica al colocar a tecnócratas — primero Lukas Papadimos en Grecia y luego Mario Monti en Italia - para "pilotar» las crisis, a pesar de que nunca habían sido elegidos por la ciudadanía para los puestos que han desempeñado. De la misma manera, la voluntad del elector griego quedó completamente irrelevante durante el verano de 2015, cuando los acreedores le dictaron al nuevo gobierno griego las condiciones de recorte y las nuevas reformas necesarias para poder acceder a un nuevo paquete de rescate ${ }^{8}$. Por lo mencionado, es comprensible que una parte de la población europea empezara a cuestionar la tesis sobre una UE como garantía del bienestar y la democracia en el Viejo Continente.

Como una tercera causa del euroescepticismo se suma la falta de una verdadera identidad —o en palabras de Toplak y Šumi (2012), de una "comunidad imaginada" europea. Si bien los «padres fundadores» de la UE eran los primeros en mostrar su conciencia acerca de la necesidad de una identidad europea basada en valores comunes, sea complementaria a, o integradora de las identidades nacionales, recién en la década de 1990 empezó a brotar el debate a nivel político, al haber desaparecido una amenaza común (la URSS), ante la perspectiva de una incorporación de nuevos países desde la Europa Central y (sur) Oriental y al haber concluido, aparentemente,

\footnotetext{
8 En las elecciones de enero 2015, la Coalición de la Izquierda Radical (o Syriza) obtuvo 149 de los 300 escaños en el Consejo de los Helenos, con un plan de gobierno muy crítico hacia las políticas de austeridad de la UE. Luego, en el referéndum de 5 de julio de 2015, un 62,5\% de los griegos votó en contra del plan de rescate propuesto por el Troika (es decir, la Comisión Europea, el Banco Central Europeo y el Fondo Monetario Internacional).

9 Los dos investigadores eslovenos se refieren a una gran obra sobre el nacionalismo: Comunidades imaginadas. Reflexiones sobre el origen y la difusión del nacionalismo del irlandés Benedict Anderson.
} 
el proceso de integración económica (Toplak y Šumi, 2012, p.12). Si bien el Tratado de Maastricht fue el primero en crear explícitamente una "ciudadanía de la Unión», más allá de los símbolos ya existentes (entre ellos, la bandera de las doce estrellas, el himno europeo, la celebración de un "Día de Europa» y eventos paneuropeos como "Eurosong») y una incipiente política cultural comunitaria en el bloque, la introducción del euro fue considerada por muchos, como un avance sin precedentes en dicha construcción de una identidad posnacional.

No obstante, la mayor parte de elementos que históricamente han contribuido al proceso de nation building en los Estados-Nación, aún se encuentran «nacionalizados» en la actualidad. Así, apenas existe una prensa masiva o una cultura popular de carácter paneuropeo, por lo que el conocimiento en una sociedad sobre los demás países miembros del bloque suele ser muy limitado. De la misma manera, en los currículos educativos escasamente hay atención por la historia o el funcionamiento de la Unión Europa y suelen predominar las visiones nacionales sobre la historia del continente. La UE además carece de algún «mito unificador» —es decir: una referencia a algún acontecimiento histórico, que se considere como antecedente del actual proceso de unificación-; visto que todas las anteriores unificaciones del continente ocurrieron bajo la fuerza.

Si la CECA de la década de 1950 aun se redujo a países de la «Europa carolingia», históricamente más interdependiente y desarrollada, dicho «núcleo duro» de la actual Unión empezó a expandirse a abarcar países de «otras» Europas: las islas británicas; la cuenca del Mediterráneo; el espacio de la Mitteleuropa, heredera del Imperio austrohúngaro; la Escandinavia, conectada con el mundo báltico, el último en la órbita del Imperio ruso; y los Balcanes, que durante siglos formaron parte del Imperio otomano. Por ello, cuando a fines de 2001 una Convención se encargaría de redactar una Constitución Europea, encontró dificultades en formular un preámbulo que sintetizaría el «legado común» de los ciudadanos de la UE: mientras que inicialmente se pensó en una referencia a las raíces judeo-cristianas, finalmente se optó por omitir cualquier alusión a un legado cultural al considerar que ello excluiría la posibilidad de incorporar nuevos países, como Turquía, que no comparten este origen. Es así que el texto de la Constitución, que nota bene se quedó en un proyecto, solamente hizo mención a ciertos «valores comunes» de carácter muy general, como elementos que históricamente habrían constituido la identidad europea ${ }^{10}$.

\footnotetext{
10 En la Constitución Europea, que jamás quedó ratificada, se hace alusión a los siguientes valores comunes: dignidad humana, libertad, democracia, igualdad, el Estado de derecho, respeto por los derechos humanos, derechos de las minorías, libre mercado, pluralismo, no discriminación, tolerancia, justicia, solidaridad e igualdad de los sexos (Comunidades Europeas, 2004).
} 
Sobre todo en épocas de crisis, donde se vio claramente la incapacidad de la Unión Europea para actuar como un bloque, y ante la falta de un real demos europeo, se ha visto un regreso del nacionalismo en varios países del bloque. La revisión temporal del Tratado de Schengen, los intensos debates en cuanto a la política de cuotas de refugiados, la construcción de muros en algunas fronteras de Europa Central, el aumento del bilateralismo - en detrimento del enfoque multilateral — para tratar con terceros países y el creciente éxito de discursos nacionalistas, proteccionistas y populistas, que acompańaron tanto a campañas electorales como la prensa popular, solamente constituyen algunos reflejos de la falta de una identidad propiamente europea de los ciudadanos de la UE.

\section{La crisis externa de la Unión Europea}

Más allá de la "crisis interna", también se puede notar una clara crisis externa del bloque consistente en, al menos, tres dimensiones: primero, la falta de influencia en, y la creciente vulnerabilidad frente a su entorno geográfico directo: el Medio Oriente y el Norte de África (a partir de aquí «MONA»); segundo, su renuencia para reconocer como un actor global y desarrollar una agenda de mutuo interés con la Federación Rusia; y tercero, la pérdida, en un nivel macro, del peso de Europa en el actual orden internacional, caracterizado por la crisis del multilateralismo, históricamente desarrollado desde el Occidente, una creciente gravedad de la cuenca del Pacífico en la economía mundial (y, con extensión, el Sur) y, con ello, la creciente multipolarización del orden.

En las tres dimensiones se mostraron claramente dos principales defectos que el bloque europeo ha traído desde sus orígenes a nivel de su proyección externa. Por un lado, la UE carece de autonomía política frente al hegemón en declive, Estados Unidos. Contrariamente a su discurso "posmoderno" o "poswestfaliano" que pone énfasis en el poder blando y económico del bloque, desde la década pasada se ha visto un creciente componente geopolítico en el perfil externo de la UE, en sí pensado desde Washington. Esta tendencia, como se mencionará más adelante, se manifiesta claramente en Europa Oriental. Por otro lado, contrariamente a la política comercial, agrícola, monetaria o de cooperación, en temas políticos Bruselas aún no habla con una sola voz, visto que la política exterior y de seguridad común básicamente ha mantenido su carácter intergubernamental (y no supranacional). Esto implica que no es la Comisión Europea, sino el Consejo de Ministros de Relaciones Exteriores, que figura como el principal encargado de dicha política, mayormente con una toma de decisiones por unanimidad, algo difícil de lograr ante los diversos, y a veces divergentes, intereses de sus veintisiete miembros. La creación, con el Tratado de Lisboa 
de 2007, de los cargos de «Presidente del Consejo Europeo» y «Alto Representante de la Unión para Asuntos Exteriores y Política de Seguridad», y de un «Servicio Europeo de Acción Exterior», apenas modificó esta modalidad.

En comparación con Estados Unidos que solo cuenta con dos vecinos, la Unión Europea se inserta en un entorno geopolítico muchísimo más complejo: en el sur se encuentran los países del Magreb; en la parte suroriental el Máshreq, el «país-pivote» Turquía y los Balcanes; y en el este los estados de la denominada «Nueva Europa Oriental» (Rusia y seis repúblicas exsoviéticas: Ucrania, Bielorrusia, Moldavia y las tres transcaucásicas). Una mayoría de los países mencionados sufre de problemas estructurales similares: una considerable debilidad estatal, aprovechada por redes criminales transnacionales $\mathrm{y} / \mathrm{u}$ organizaciones terroristas; economías altamente desiguales y estancadas, incapaces de ofrecer oportunidades a la mayoría de población; y la politización y exacerbación de las diferencias étnicas y religiosas. Más allá de dichos vecinos directos, en regiones como el Sahel o países específicos como Yemen, Afganistán o Pakistán, la situación es francamente dramática. En este sentido, algunos autores, como Jonathan Holslag (2015), incluso hablan en términos de un «Arco de Inestabilidad» ubicado alrededor de la UE.

A fin de profundizar las relaciones bilaterales entre el bloque y sus vecinos directos del sur y este, en 2004 se estrenó la «Política Europea de Vecindad». Si bien este programa oficialmente buscó un mayor «diálogo» con los dieciséis socios inscritos diez del MONA y seis repúblicas exsoviéticas-, en la práctica se trata de un sistema, tildado por sus críticos como paternalista, que impulsa las reformas políticas, institucionales, comerciales y económicas, a cambio de fondos económicos, una flexibilización del régimen de visas y un mayor acceso al mercado europeo. No obstante, con el inicio de la Primavera Árabe no solamente se demostró la inadecuación del enfoque, sino también la escasa influencia que Europa, en general, tiene en la zona. En este sentido, no ha habido una gran diferencia desde la década de 1990, cuando Bruselas tampoco tuvo un papel importante a jugar en los sangrientos conflictos de Croacia y Bosnia Herzegovina. Con la excepción de Libia, donde Francia y el Reino Unido lideraron la intervención militar contra el régimen de Muamar Gadafi, y la participación de países europeos individuales en ataques aéreos contra Daesh en Iraq y Siria, el bloque europeo no ha mostrado un papel crucial en el MONA, en comparación con Estados Unidos, la Federación Rusa o potencias regionales como Arabia Saudita, Irán o Turquía. Además, a pesar del discurso a favor de la democratización y los derechos humanos, la Unión manejó un discurso altamente cauteloso y ambiguo, similar a la administración de Barack Obama, ante las movilizaciones de millones de ciudadanos, la posterior caída de líderes como Mubarak y Ben Ali, con los cuales la UE había trabajado intensamente, y un aparente empoderamiento del 
Islam político. La cercanía geográfica de varios países devastados por la guerra o de economías sin oportunidades, la creciente movilidad de las personas, la visible indiferencia europea frente a sus "vecinos» en problemas, más la presencia de millones de migrantes de descendencia musulmana — no todos ellos plenamente integradosha originado varios efectos spill-over: el arribo de cientos de miles de refugiados, el creciente activismo de células o «lobos solitarios», supuestamente vinculados a Daesh y, con ello, una creciente percepción en el continente europeo de estar bajo amenaza, por primera vez desde la Segunda Guerra Mundial.

La segunda dimensión de la crisis externa de la Unión Europa refiere al deterioro de las relaciones con la Federación Rusa, un tema donde además se ha mostrado el creciente componente geopolítico de la proyección externa del bloque. Cuando recién había caído el Muro de Berlín, ganó relevancia la idea gaullista de una «Europa desde el Atlántico hasta los Urales» y el similar concepto de Michael Gorbachov sobre una "Casa Común Europea», aludiendo en ambos casos a un espacio europeo pluralista y multipolar, basado en la entonces Comunidad Europea, Rusia, Turquía e incluso Ucrania, como socios iguales. Dicha representación además constituyó la filosofía atrás de la Carta de París, adoptada durante la segunda Conferencia para la Seguridad y la Cooperación en Europa (1990); la ampliación del Consejo de Europa en los años siguientes ${ }^{11}$; y el lanzamiento en 1994 de la Asociación para la Paz, un programa para estrechar las relaciones entre la OTAN, los exmiembros del Pacto de Varsovia y los estados neutros del Viejo Continente.

Sin embargo, ante el rápido debilitamiento de Rusia, causado por la disolución de la Unión Soviética y la catastrófica transición a una economía de mercado, paulatinamente se empezó a imponer otra versión de una Europa unificada: la expansión desde Bruselas de la propia Unión Europea, con sus respectivos valores políticos y económicos, en alianza con Estados Unidos. Fue según esta última perspectiva que países como Polonia, Chequia o los bálticos — los mismos que Donald Rumsfeld describiría como la «Nueva Europa», por su energético apoyo a las políticas estadounidenses y sus posturas rotundamente antirrusas - empezaron a referirse a su «regreso a Europa», al incorporarse a la Unión. En esta segunda versión de Europa, que Richard Sakwa denomina la «Europa atlantista» o la «Gran Europa» (en contraste con la «Europa amplia», de carácter pluralista), la Federación Rusa quedó tildada como el bando perdedor de la Guerra Fría — y no como un actor mundial relevante- (2015, pp. 558-559). Desde esta misma lógica, la UE iniciaría con la incorporación, parale-

\footnotetext{
11 Actualmente (2017), el Consejo de Europa cuenta con 47 miembros: todos los países europeos salvo Bielorrusia, Kazajistán, Kosovo y el Vaticano. Si bien Armenia geográficamente no está ubicada en Europa, sí forma parte del organismo.
} 
lamente a la OTAN, de todos los exintegrantes del Pacto de Varsovia (desde Polonia hasta Bulgaria) y tres de la misma ex Unión Soviética (el Báltico). Luego apoyaría las movilizaciones, conjuntamente con Estados Unidos, que surgieron en el marco de las denominadas «Revoluciones de Colores», en Georgia (2003), Ucrania (2004) y Kirguistán (2005), y apenas se inmutaría cuando en 2005 George Bush Jr. lanzó su Sistema de Defensa Antimisiles, a instalarse principalmente en los países del este de la UE, supuestamente dirigido en contra de la amenaza iraní. Finalmente, la UE estrenaría, en 2009, la "Asociación Oriental» que busca el establecimiento de acuerdos de asociación entre el bloque y otras seis repúblicas exsoviéticas: Bielorrusia, Ucrania, Moldavia, Georgia, Azerbaiyán y Armenia. Si el comercio constituye el principal tema en dichas negociaciones, también incluye dossiers importantes como el régimen de visa, la promoción de los derechos humanos y la democracia y hasta asuntos de seguridad y defensa, todo ello sin ningún tipo de coordinación previa con Moscú, el histórico hegemón en la zona.

Dicha política occidental excluyente hacia Rusia quedó criticada crecientemente desde el Kremlin a partir del segundo gobierno de Yeltsin y, luego, durante los dos primeros gobiernos de Putin y el de Medvedev. No obstante, recién fue con el tercer gobierno de Putin, cuando la Federación Rusa una vez recuperada dramáticamente a nivel internacional, que se observaría una crisis en la arquitectura de seguridad europea — tildada por algunos como la «Guerra Fría 2.0»— en países como Moldavia, Georgia y, el caso más emblemático, Ucrania. Esta crisis fue descrita de la siguiente manera por Richard Sakwa, en uno de los mejores artículos publicados sobre los efectos para el continente europeo del conflicto ucraniano, «The Death of Europe? Continental fates after Ukraine»:

The EU suppressed recognition of its own geopolitical ambitions, couching its advance in the language of regulation, good governance and normative institutions. These are important and fundamental goods, but their assertion without recognition of the internal and external complexities of the target country represents geopolitical nihilism of the highest order. This nihilism was couched in the language of an amorphous Atlanticism that, like the mimetic Cold War, displaced responsibility to what has now become the hermetic ideology of transdemocracy, where democratic advance is associated with subordination of the security structures of the new Atlanticism. The $\mathrm{EU}$ is in danger of being subsumed into the new Atlanticism, thereby losing its autonomous sense of purpose and responsibility. Instead of advancing the peaceful integration of Europe on a clearly articulated pan-continental basis, the EU became the unwitting instrument for new dividing lines across the continent (2015, pp. 578-579).

En otras palabras: las normas de «buen gobierno» abocadas por la UE hacia países de su "periferia» se han vuelto politizadas a raíz de la creciente convergencia entre la UE y la OTAN, manifiesta desde hace más de una década. De esta manera, mientras 
que la política de promoción de la democracia y la integración económica es vista por Bruselas como benigna, fuente de mayor seguridad en el continente europeo y muestra de su poder blando, Moscú la considera como amenazante, desestabilizadora y, sobre todo, como parte de una nueva política de contención ejercida por el Occidente en contra de las principales potencias neorrevisionistas de Eurasia: Rusia, China e Irán.

Una última dimensión de la crisis externa de la Unión Europea que queremos mencionar tiene que ver con una dinámica de carácter más estructural: el declive relativo de los recursos de poder del bloque (y el continente europeo, en general) a nivel mundial, en paralelo con los principales elementos del actual orden internacional. En este momento, tomado como agregado, la Unión Europea (UE-27) representa la segunda economía del mundo (22\% del PBI mundial), cuenta con la segunda moneda de mayor circulación (el euro), figura como el primer donante de ayuda humanitaria $(54 \%)$ y constituye la tercera fuerza militar, en términos de gastos ${ }^{12}$ (CE, 2017; SIPRI, 2017). No obstante, hay una clara tendencia de declive. Así, por ejemplo a nivel de la población: mientras que los europeos aún representaban el $25 \%$ en 1900, hoy solo son un 6\% y para 2060 se proyecta una población europea de apenas 4\% del mundo (CE, 2017). Además, para 2030, Europa tendría la población más vieja del mundo: su edad media será de 45 años, contra 40 en América del Norte, 35 en Asia, 34 en ALC y apenas 21 años en África (CE, 2017). Algo similar sucede con la parte europea en el PBI mundial: si en 2004 aún representaba el 26\%, en 2015 ya se había reducido a un 22\% y para 2030 llegaría a representar un porcentaje inferior al 20\% (CE, 2017).

Todo ello coincide con lo que algunos analistas hayan descrito como el creciente "giro» hacia la cuenca del Pacífico - en detrimento del Atlántico que durante cinco siglos constituyó el centro de gravedad del mundo-. Pero la transformación es más compleja que este giro horizontal, ya que además se percibe un notable empoderamiento económico, acompañado por una notable concientización política, por parte de varios países del Sur, entre otros, Brasil, Sudáfrica, Nigeria, India, Indonesia, Bangladés, Vietnam y, obviamente, la República Popular China.

Paralelamente al declive relativo del Viejo Continente respecto a otros polos de poder en el mundo, hay otra tendencia que se encuentra en pleno desarrollo en el actual orden internacional: el regreso de las denominadas "políticas de poder» (del inglés: power politics), las que se manifiestan en diversos ámbitos. Primero, en el ámbito de seguridad: si bien en este momento no hay mayores conflictos interesta-

12 Según cifras del SIPRI sobre los gastos militares realizados en el año 2016, Estados Unidos gastó unos 611 mmd,
China 215 mmd, la UE-27 198 mmd, Rusia 69 mmd y el Reino Unido 48 mmd (SIPRI 2017). 
tales, sí hay una tendencia de militarización en varias regiones del mundo: el Asia Oriental, Suroriental y Meridional y la península arábiga. De la misma manera, en el dominio económico se puede constatar un «regreso del Estado» respecto al Consenso de Washington que predominó en el mundo durante tres décadas y, con ello, un renovado proteccionismo en varios países, crítico hacia la narrativa globalizadora y librecambista de la década de 1990.

Finalmente, desde finales de la década pasada se observa un claro retroceso en la «Tercera Ola de Democratización», ante el aumento de los golpes (del tipo militar, «auto» o «institucional») contra gobiernos democráticamente elegidos, un deterioro de la situación de los derechos humanos a nivel mundial y una alarmante pérdida de confianza por parte de la opinión pública en el régimen democrático. Dichas tendencias no solamente explican la crisis actual del multilateralismo creado durante la primera etapa de la hegemonía estadounidense. También contribuyen con la pérdida de influencia de la UE, históricamente asociada con un discurso a favor de la cooperación interestatal, el multilateralismo y valores como la democracia, los derechos humanos, el desarrollo sostenible y la igualdad. Para así decirlo: durante varias décadas, el papel internacional de la Unión coincidió con el de su principal miembro, la Zivilmacht Alemania: una potencia «civilizadora» de las relaciones internacionales, promotora de valores, y que basa su poder en sus recursos económicos y la baja política, en vez de recursos militares. Sin embargo, tal como lo admite JeanClaude Juncker, el actual presidente de la Comisión Europea, en su Libro Blanco de 2017: «Ser un "poder blando» ya no es suficiente cuando la fuerza puede prevalecer sobre la ley» (CE, 2017, p. 9).

Ante este nuevo escenario crecientemente multipolar y "posoccidental», tal vez más que los propios Estados Unidos, la UE aún se muestra incómoda y carente de una estrategia a largo plazo. Queda por verse si el ingreso en 2015 de varios países europeos, miembros de la Unión, al Banco Asiático de Inversiones en la Infraestructura, el creciente diálogo con China respecto a la realización del OBOR —entre otros temas, como el comercio y el medio ambiente- y la aumentada atención en documentos oficiales de la UE hacia el multipolarismo, realmente constituirán las bases de un cambio de mentalidad frente a la nueva realidad. O si, más bien, la UE necesitará pasar por una etapa más larga en el tiempo para encontrar su nueva misión en un mundo transformado, coincidiendo así con la expresión de Dean Acheson de 1962 sobre el Reino Unido: «it lost an Empire, but not yet found a role». 


\section{El futuro y las conclusiones}

Aparentemente, el año 2017 no será tan desastroso como algunos analistas lo habían anticipado. Por primera vez desde 2008 hay muestras de un crecimiento económico sólido, manifiesto en todos los miembros del bloque (se proyecta un crecimiento anual de $1,6 \%$ ), y unas tasas de desempleo en niveles precrisis (aunque $8 \%$ sigue siendo alto en comparación con otras economías). Además, en las elecciones de Países Bajos y Francia - y probablemente también en las alemanas de setiembreganaron los candidatos proeuropeístas y con el decepcionante resultado para el Partido Conservador en las snap elections británicas se ha fortalecido claramente la posición del bloque ante las negociaciones sobre el Brexit.

Por otro lado, como consecuencia de un control más rígido de las fronteras y del controversial acuerdo firmado con Turquía en 2016, se ha visto una reducción considerable en el número de solicitantes de asilo en la Unión Europea: de más de un millón en 2015 a unos 360 mil en 2016, quitando así terreno a la extrema derecha. Finalmente, las mismas acciones del presidente Trump han originado llamados cada vez más fuertes a favor de una política europea más autónoma frente al socio tradicional, Estados Unidos. En este sentido, el flamante presidente francés ya le propuso a la canciller alemana una mayor cooperación europea a nivel de defensa y la organización de convenciones nacionales para consultarle a la población sobre el futuro del bloque. Así, la salida de un histórico poder-veto de la Unión y la posible reactivación del eje París-Berlín como motor de la profundización del proyecto integrador, parecen ser elementos prometedores para el futuro de la UE.

Sin embargo, como hemos visto a lo largo del presente artículo, la mayor parte de las causas que han originado las diversas crisis de la UE en los últimos ańos son de carácter estructural. Por lo tanto, recién se podrá hablar de un proyecto regionalista europeo sostenible y, como resultado, una voz europea influyente en el nuevo concierto internacional, cuando se logre:

- Democratizar las instituciones de la UE, en detrimento de su perfil tecnócrata actual, mediante una conversión del actual Parlamento en un parlamento verdadero y de la Comisión en un gobierno plenamente responsable ante dicha institución;

- Profundizar la unión hacia otros terrenos no comerciales, como las políticas sociales, las económicas y las de defensa; y cuestionar el paradigma económico actual del bloque, demasiado enfocado en la estabilidad de precios. 
- Implementar una estrategia coherente y a largo plazo, a fin de reducir la brecha entre las economías del norte y las «periféricas» del sur y del este, a nivel de competitividad, desempleo y, en general, bienestar;

- Revisar las políticas, hoy altamente ambiguas y paternalistas, frente a los vecinos del sur, sobre todo los del MONA;

- Materializar una mayor autonomía de Estados Unidos en el tema de seguridad, para así también poder revisar la relación bilateral con la Federación Rusa, iniciando con su reconocimiento como importante interlocutor en varias agendas;

- Reconocer la transformación del orden internacional a fin de asumir una postura más modesta frente a las nuevas potencias del este y sur del mundo.

No es la primera vez que se ha cuestionado existencialmente al proyecto de integración europeo. No obstante, la última década sí ha constituido la mayor crisis desde sus orígenes. Las «soluciones» para darle un nuevo ímpetu al proyecto son conocidas... desde hace tiempo. El contexto actual parece ser oportuno para cuestionar aquellas políticas que no han resultado. A ver si las élites políticas pueden regresar a las tres razones de ser de la Unión Europea: garantizar el bienestar de su población, promover la paz y la democracia en Europa y darle una voz (autónoma) a los europeos en la comunidad internacional.

\section{Referencias}

Ash, T.G. (2012). The Crisis of Europe. How the Union Came Together and Why It's Falling Apart. Foreign Affairs, 91(5), 2-15.

Comisión Europea (2017). Libro Blanco sobre el Futuro de Europa. Reflexiones y escenarios para la Europa de los Veintisiete en 2025. Bruselas: CE.

Comunidades Europeas (2004). Tratado por el que se establece una Constitución para Europa. Luxemburgo: Oficina de Publicaciones Oficiales de las Comunidades Europeas.

Holslag, J. (2015). De kracht van het paradijs. Hoe Europa kan overleven in de Aziatische eeuw. Ámsterdam: De Bezige Bij.

Kundnani, H. (2015). The Paradox of German Power. Londres: Hurst Publishers. https://doi. org/10.1093/acprof:oso/9780190245504.001.0001

Moreno Juste, A. (2009). El proceso de construcción europea: de la CECA al Tratado de Maastricht. En J. C. Pereira Castañeras, Historia de las Relaciones Internacionales Contemporáneas (pp. 561-584). Madrid: Ariel.

Nancy, J. (2017). Two years until the 2019 European elections. Special Eurobarometer of the European Parliament. Bruselas: European Parliamentary Research Service.

Rummens, S. (2016). Wat een theater! Politiek in tijden van populisme en technocratie. Kalmthout: Pelckmans Pro. 
Sakwa, R. (2015). The death of Europe? Continental fates after Ukraine. International Affairs, 91(3), 553-579. https://doi.org/10.1111/1468-2346.12281

Toplak, C. e I. Šumi. (2012). Europe (an Union): Imagined Community in the Making? Journal of Contemporary European Studies, 20(1), 7-28. https://doi.org/10.1080/147 82804.2012.656949

Unión Europea(2016). Shared Vision, Common Action: a Stronger Europe. A Global Strategy for the European Union's Foreign and Security Policy. Bruselas: UE.

Van Meurs, Wim, Robin de Bruin, Carla Hoetink, Karin van Leeuwen, Carlos Reijnen, Liesbeth van de Grift (2013). Europa in alle Staten. Zestig jaar geschiedenis van de Europese integratie. Nijmegen: Uitgeverij Vantilt.

Fecha de recepción: 5 de junio de 2017 Fecha de aprobación: 27 de junio de 2017 